\title{
IMPLEMENTATION OF SEQUENTIAL DESORPSION IN DETERMINING Cd (II) ION INTERACTION WITH ADSORBENT OF IONIC IMPRINTING AMINO-SILICA HYBRID
}

\author{
Buhani $^{1, *}$, Suharso ${ }^{1}$, M. Rilyanti ${ }^{1}$, and Sumadi ${ }^{2}$ \\ ${ }^{1}$ Department of Chemistry, Faculty of Mathematic and Natural Sciences, University of Lampung \\ Jl. Prof. Dr. Sumantri Brojonegoro No. 1, Bandar Lampung, Indonesia \\ ${ }^{2}$ Department of Electrical Engineering, Faculty of Engineering, University of Lampung \\ Jl. Prof. Dr. Sumantri Brojonegoro No. 1 Bandar Lampung, Indonesia \\ *E-mail: buhani_s@yahoo.co.id
}

\begin{abstract}
Interactions of $\mathrm{Cd}$ (II) ion in solution with the adsorbent of amino-silica hybrid or non-imprinted polymer (NIP) and Cd (II) ionic imprinting (Cd (II)-IIP) have been studied through a sequential desorption process. The adsorbent of NIP and Cd (II)-IIP were synthesized from 3-aminopropyltrimethoxysilane (3-APTMS) and tetraethylortosilicate (TEOS). The value of the Specific surface area, total porous volume, and Cd (II)-IIP porous diameter is each $29.010 \mathrm{~m}^{2} \mathrm{~g}^{-1}$, $0.100 \mathrm{~mL} \mathrm{~g}^{-1}$, and $30.452 \AA$. The interaction contribution of $\mathrm{Cd}$ (II) ion was determined by the sequential desorption with water eluent, $\mathrm{KNO}_{3} 1 \mathrm{M}, \mathrm{HONH}_{2} \mathrm{HCl} 0.3 \mathrm{M}$ in $25 \%$ (v/v) $\mathrm{CH}_{3} \mathrm{COOH}$, and $\mathrm{Na}_{2} \mathrm{EDTA} 0.1 \mathrm{M}$. The sequential desorption result showed that a tendency of Cd (II) ion interaction contribution on NIP and Cd (II)-IIP increased with order of ion exchange interaction $<$ entrapment $<$ complex formation $<$ hydrogen bond.

Keywords: sequential desorption, amino-silica hybrid, adsorption mechanism, Cd metal
\end{abstract}

() RASĀYAN. All rights reserved

\section{INTRODUCTION}

Several types of research of heavy metal ion ${ }^{1-6}$ and dyestuff ${ }^{7-9}$ controlling through an adsorption process have been done by some researchers. The adsorption process in solution phase was usually found in adsorption of heavy metal in solution using various kind adsorbents in the scale of laboratory and macro in controlling industrial liquid waste. The solution adsorption process is generally more difficult theoretically than the adsorption process in the phase of gas, favor, or pure liquid. This is due to the adsorption of the solution involving the competition between solutes and solvents or between the liquid mixed components and the adsorption site ${ }^{10}$. The adsorption process of the solution can be predicted qualitatively from the polarity of the adsorbent and the solution components. Polar adsorbents tend to absorb stronger polar adsorbates than non-polar adsorbates and vice versa. The adsorption strength is the result of a combination of the adsorbate affinity of the adsorbent.

The metallic ion adsorption kinetics in the solution phases have been studied as adsorption of $\mathrm{Cd}$ (II), $\mathrm{Pb}$ (II), and Ni (II) ions in brown algae ${ }^{11}$, adsorption of Nickel on Gracilaria caudata and Sargassum muticum ${ }^{12}$, adsorption of Cd (II) ions on Nannochloropsis sp ${ }^{13,14}$. A special study of the process of adsorption of metal ions on the printed ion adsorbents which has been widely performed is the determination of the capacity and selectivity of metal ion adsorption ${ }^{15-19}$. However, the results of this study have not specifically discussed the interaction of metal ions with adsorbents. The adsorption mechanism is an important part of the study of metallic ion adsorption kinetics, since the adsorption mechanism can provide an overview of the interactions that occur between metal ions (adsorbate) and adsorbents. In the adsorption process, it is always desirable that the amount of metal ions adsorbed more and is easily released (desorption) back. In this case the strong or weak interaction between the adsorbed metal ions will be known by determining the reaction mechanism between metal ions and adsorbents. 
In this study, it was studied the contribution of Cd (II) ion interaction with NIP and Cd(II)-IIP adsorbent to find out the adsorption mechanism of $\mathrm{Cd}$ (II) ion by desorption method. The desorption process used a sequential method with removing the adsorbed Cd (II) ions on the adsorbent in sequence. The process of desorption was performed using various types of eluent consisting of water, $\mathrm{KNO}_{3} 1.0 \mathrm{M}, \mathrm{HONH}_{2} \mathrm{HCl} 0.3$ $\mathrm{M}$ in $25 \%(\mathrm{v} / \mathrm{v}) \mathrm{CH}_{3} \mathrm{COOH}$, and $\mathrm{Na}_{2}$ EDTA $0.1 \mathrm{M}$.

\section{Material}

\section{EXPERIMENTAL}

The materials used in the synthesis of NIP and Cd (II)-IIP as well as the adsorption-desorption process include 3-APTMS compounds, derived from Aldrich. $\mathrm{CdCl}_{2} \cdot \mathrm{H}_{2} \mathrm{O}$, TEOS, $\mathrm{Na}_{2} \mathrm{EDTA}, \mathrm{KNO}_{3}, \mathrm{HONH}_{2} \mathrm{HCl}$, acetic acid, $\mathrm{CH}_{3} \mathrm{CH}_{2} \mathrm{OH}, \mathrm{CH}_{3} \mathrm{COONa}$, Whatman 42 filter paper, and Universal indicator paper are from EMerck. While, $\mathrm{HCl}$ and $\mathrm{NaOH}$ are from Alba.

\section{Instrumentation}

The tools used include glassware, analytical scales, crusher, 200 mesh sieve, heater, magnetic stirrer, centrifuge, and $\mathrm{pH}$ meter. The metal concentration was measured by atomic absorption spectrophotometer (AAS) Model 3110, Perkins Elmer. The surface area, total pore volume, and pore diameter of the adsorbent were investigated by the Nova 1200e Quanta chrome surface area analyzer.

\section{Procedure}

\section{Synthesis of NIP and Cd (II)-IIP}

The synthesis of Cd (II)-IIP adsorbents was carried out using a 3-APTMS compound. The solution preparation was divided into two parts: solution I was prepared from TEOS and water mixture $(1: 1)$ and a $1 \mathrm{M} \mathrm{HCl}$ solution ( $\mathrm{pH}$ 2) was then stirred with a magnetic stirrer for 30 minutes. Solution II was prepared from $5 \mathrm{~mL}$ of ethanol with 0.2013 grams of $\mathrm{CdCl}_{2} \cdot \mathrm{H}_{2} \mathrm{O}$ dissolved with stirring. It is then added to the 3APTMS compound and stirred until homogeneous. The solution I was mixed with solution II with stirring using a magnetic stirrer until homogeneous and gel form. The formed gel was allowed for 24 hours to form a completely solid, then the synthesis solids are rinsed with a 60/40\% water/ethanol mixture and continued by soaking the solids for 24 hours in $0.1 \mathrm{M} \mathrm{Na}_{2}$ EDTA solution. Furthermore the solid was soaked and stirred for 30 minutes in a $0.5 \mathrm{M} \mathrm{HCl}$ solution. The produced solid was neutralized with distilled water up to $\mathrm{pH} \approx 7$ and dried to constant weight at $60{ }^{\circ} \mathrm{C}$. Dry material was crushed to 200 mesh. The same treatment was given to synthesis of HAS without the addition of $\mathrm{CdCl}_{2} \cdot \mathrm{H}_{2} \mathrm{O}^{20}$.

\section{Contribution of interaction}

To determine the mechanism of metal ion adsorption begins with the adsorption process using $50 \mathrm{~mL}$ of Cd (II) $500 \mathrm{mg} \mathrm{L}^{-1}$ solution at $100 \mathrm{mg}$ of Cd (II)-IIP adsorbent. Investigation of adsorption mechanism was performed by sequential desorption experiment. The desorption was done by desorbing Cd (II) ion adsorbed on the adsorbent by using $50 \mathrm{~mL}$ of a solution whose different desorption forces were water, $\mathrm{KNO}_{3} 1 \mathrm{M}$, $\mathrm{HONH}_{2} \mathrm{HCl} 0.3 \mathrm{M}$ in $25 \%$ (v / v) $\mathrm{CH}_{3} \mathrm{COOH}$ and $\mathrm{Na}_{2}$ EDTA $0.1 \mathrm{M}$.

\section{Surface Area, Size, and Distribution of Adsorbent Pores}

\section{RESULTS AND DISCUSSION}

Determination of total pore volume, specific surface area, and pore diameter of NIP and Cd (II)-IIP compared with silica gel can be seen from the analysis by using surface area analyzer (Table-1). In Table1 , it can be observed that NIP and Cd (II)-IIP have a specific surface area and the total pore volume which is relatively smaller than that of silica gel. Modification of silica with 3-APTMS causes the silica surface to be closed by the active compound, so that the specific surface area decreases. This is due to the interaction of organic molecules on the surface of the silica explaining the fact that there is a pendant (related) group that blocks the adsorption of nitrogen gas ${ }^{21,22}$. The alkyl bond fills the space within the silica pore which causes a decrease in pore volume ${ }^{23}$. 
RASĀYAN J. Chem.

Vol. 11 | No. 2 |865 - 870 | April - June | 2018

Table-1: Results of Surface Analysis of Silica, NIP, and Cd (II)-IIP

\begin{tabular}{cccc}
\hline Material & $\begin{array}{c}\text { Specific Surface Area } \\
\left(\mathrm{m}^{2} \mathrm{~g}^{-1}\right)\end{array}$ & $\begin{array}{c}\text { Total Pore Volume } \\
\left(\mathrm{mL} \mathrm{g}^{-1}\right)\end{array}$ & Pore Diameter (A) \\
\hline Silica & 199.801 & 0.272 & 54.498 \\
NIP & 87.873 & 0.350 & 50.672 \\
Cd(II)-IIP & 29.010 & 0.100 & 30.452 \\
\hline
\end{tabular}

Nitrogen adsorption-desorption isotherm patterns from NIP and Cd (II) -IIP (Fig.-1) show similar patterns. This indicates that there is no significant influence on the surface structure of the adsorbents because of the ion imprinting process. In Fig.-1 shown in the low P/Po region, a horizontally inclined appearance indicates absorption at small pore volume. In the higher $\mathrm{P} / \mathrm{Po}$ region, there is an increasing pattern of adsorption indicating adsorption in larger pore volume. The NIP and Cd (II) -IIP materials generally follow a mixture of type I and IV adsorption isotherms according to the Brunnauer classification. The type I adsorption isotherm pattern only forms one layer of adsorbate only and occurs only in the process of chemisorption. The IV type adsorption isotherm pattern occurs in the higher P/Po region with hysteresis loop type H1 indicating mesoporous material. From Fig.-1 it can be observed that the hysteresis loop on Cd (II)-IIP is weaker than NIP due to decreased pore volume after functionalization and ionic imprinting process ${ }^{24}$.
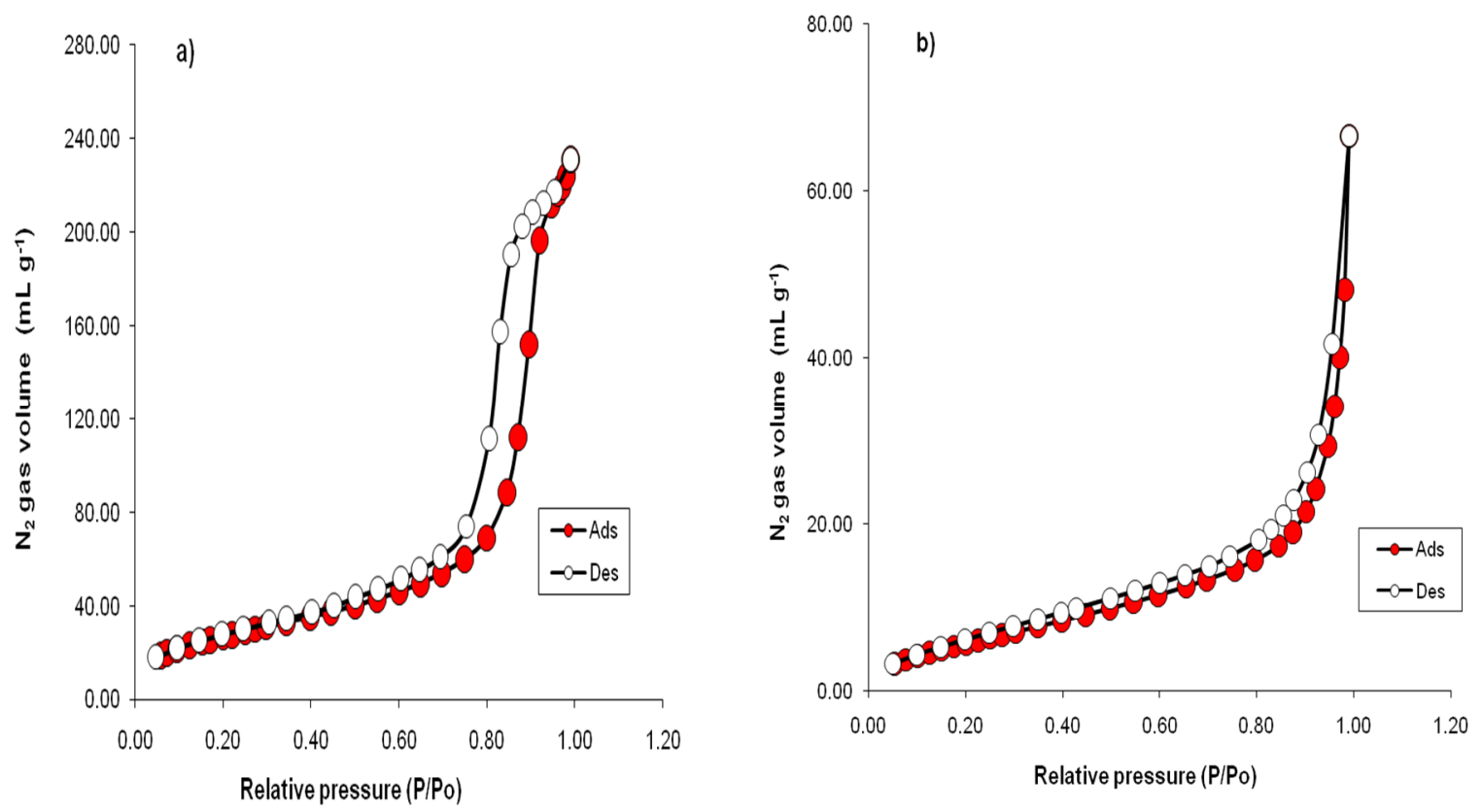

Fig.-1: Isotherm pattern of nitrogen adsorption-desorption in (a) NIP and (b) Cd (II)-IIP

\section{Interaction Contribution}

In this research, it was performed desorption of Cd (II) ion adsorbed on Cd (II)-IIP material to find out the mechanism of adsorption. Desorption with water is expected to illustrate the contribution of the entrapment mechanism to the adsorption process. The $\mathrm{KNO}_{3}$ solution was used to explain the ion exchange contribution. The contribution of the hydrogen bonds in the adsorption of the $\mathrm{Cd}$ (II) ion is carried out by desorption of $\mathrm{HONH}_{2} \mathrm{HCl} 0.3 \mathrm{M}$ in $25 \%$ (v / v) $\mathrm{CH}_{3} \mathrm{COOH}$. The $\mathrm{HONH}_{2} \mathrm{HCl}$ molecules are able to bind strongly through hydrogen bonds because they have a hydroxyl group $\left(\mathrm{OH}^{-}\right)$. The use of $\mathrm{Na}_{2} \mathrm{EDTA}$ aims to desorb Cd (II) ions adsorbed through the formation of complexes. The EDTA ${ }^{2-}$ ion is a very strong chelating ligand so that the metal ions bonded to the adsorbent will be resorbed by the formation of a relatively stable Cd (II)-EDTA complex at a value of $\log k_{l}=16.36^{25}$.

In Fig.-2 it can be observed that the tendency of contribution of Cd (II) ion interaction on Cd (II)-IIP material increases with the sequence of ion exchange mechanism $<$ entrapment $<$ complex formation $<$ 
hydrogen bond. The contribution data of Cd (II) ion interactions on NIP and Cd (II)-IIP materials (Fig.-2) shows the mechanism of trap more likely to occur on NIP than Cd (II)-IIP. This is due to the relatively larger pore size of Cd (II)-IIP. The pore diameter of the NIP material is $50.672 \AA$ while the Cd (II)-IIP is $30.452 \AA$ (Table 1), allowing to adsorb Cd (II) ions in a hydrated form.

Adsorbent NIP and Cd (II)-IIP have active groups such as $-\mathrm{OH}$ groups and amines ${ }^{26}$. For ion exchange mechanisms on NIP and Cd (II)-IIP both are relatively small (about 4\%). The contribution of ion exchange to divalent metal ions in the material may occur when the affinity of the $-\mathrm{OH}$ and the amine group on the adsorbent is good to the metal ion. However, based on its hardness, the $-\mathrm{OH}$ and amine groups are hard bases while the Cd (II) ions are soft acids so that based on Pearson's Hard and Soft Acids and Bases (HSAB) theory ${ }^{27}$ there is no suitability of characteristic of the hardness and softness between the Cd (II) ions with the active groups on HAS or Cd (II)-IIP, thus minimizing the possibility of interaction through ion exchange.

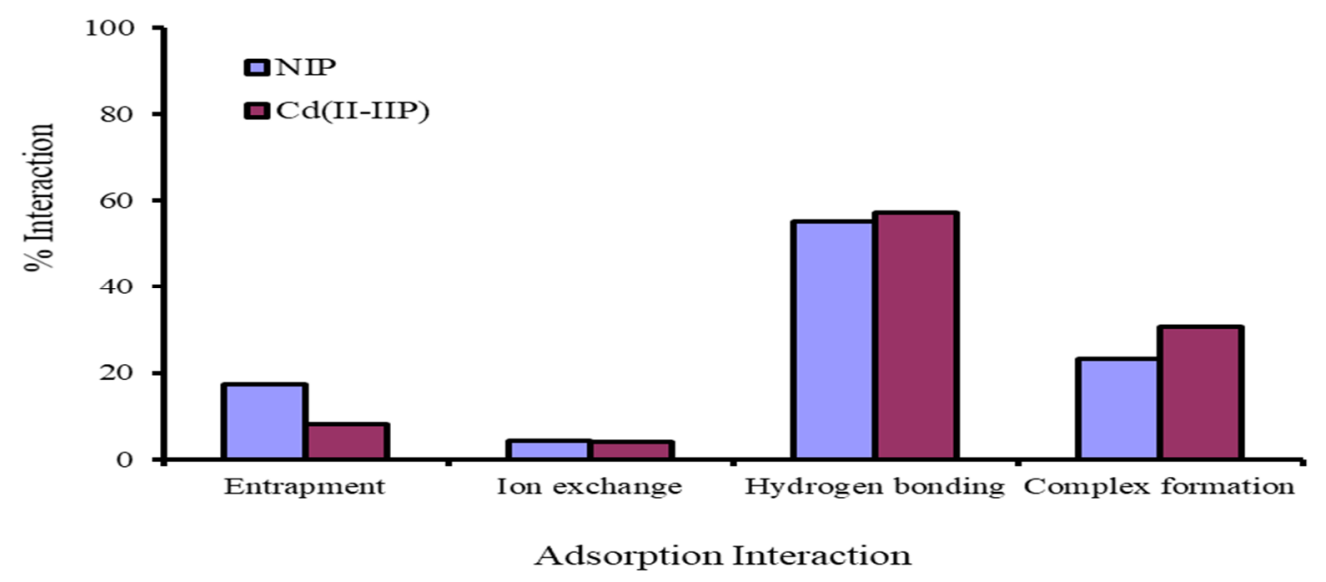

Fig.-2: Contribution of Cd (II) ion interactions on NIP and Cd (II)-IIP materials

a)

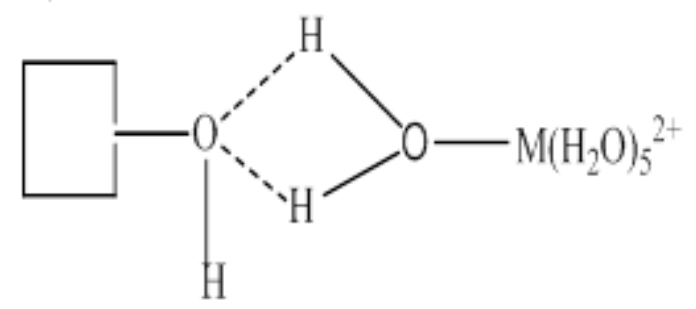

b)

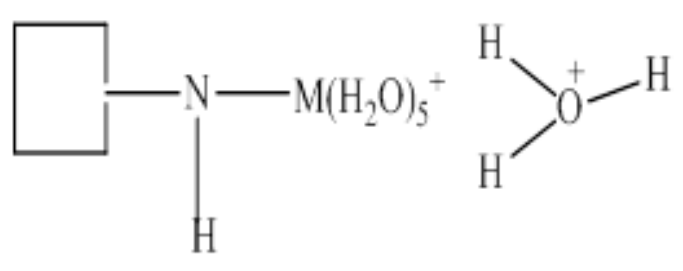

Fig. -3: Mechanism of interaction of metal ions and adsorbents through the formation of (a) Hydrogen bond and (b) Complexes in solution

The mechanism of forming hydrogen bonds (Fig.-3a) further affects the interaction of metal ions and NIP and Cd (II)-IIP materials compared to the mechanism of trap and ion exchange. Cd (II) ions in water are in species $\left[\mathrm{CdOH}\left(\mathrm{H}_{2} \mathrm{O}\right)_{5}\right]^{+}$and $\left.\left[\mathrm{Cd}(\mathrm{OH})_{2}\left(\mathrm{H}_{2} \mathrm{O}\right)_{4}\right]\right)^{28}$. The presence of $\mathrm{H}_{2} \mathrm{O}$ bound to Cd (II) ions can be used to form hydrogen bonds with an adsorbent active group. The ion imprinting process does not increase the contribution of hydrogen bonding to $\mathrm{Cd}$ (II)-IIP, so it can be expressed that the $\mathrm{Cd}$ (II) ion imprinting process does not alter the surface structure of the adsorbent, but increases the selectivity to Cd (II) ions ${ }^{20}$. The adsorption mechanism of Cd (II) ions on NIP and Cd (II)-IIP also occurs through the formation of the complex (Fig. 3b). In Cd (II)-IIP occurs increasing the contribution of complex formation compared to NIP. Mechanisms can occur influenced by the presence of active groups on materials such as silanol, siloxane and amine groups ${ }^{20}$. The mechanism of formation of complexes between Cd (II) ions with NIP 
and Cd (II)-IIP has a lower contribution than the formation of hydrogen bonds. This is thought to be due to the form of metal ions in the form of a hydrated complex will be more likely to form hydrogen bonds with the active group.

Another possibility is that the presence of $\mathrm{H}_{2} \mathrm{O}$ in the hydrated complex blocks the interaction between metal ions and the adsorbent active group, resulting in relatively few complexes. It is also supported by the nature of hard and soft acid-base, the Cd (II) ion is classified as soft acid while the active group on the adsorbent is more dominated by hard bases such as the $-\mathrm{OH}$ and amine group ${ }^{26}$, so the interaction of the soft acid and hard base tends to be less favorable based on the HSAB Pearson concept ${ }^{27}$.

In this study, the interaction between Cd (II) ions with NIP and Cd(II)-IIP adsorbents dominated by the hydrogen bond formation mechanism shows that $\mathrm{Cd}$ (II) ion interaction with the adsorbent is not too strong, so that the adsorbed Cd (II) ions are easily removed and the adsorbent can be used in repeated adsorption. The fact of low interaction between metal ions and other adsorbents was also found on adsorption of $\mathrm{Zn}$ (II) and $\mathrm{Ni}(\mathrm{II})$ onto cloves (Syzygium aromaticum) ${ }^{29}$, Adsorption of $\mathrm{Ni}(\mathrm{II}), \mathrm{Cu}(\mathrm{II})$, and $\mathrm{Zn}$ (II) ions on modification of Tetraselmis sp. biomass ${ }^{1}$, adsorption of several heavy metal ions on activated carbon ${ }^{30}$, and adsorption of heavy metals on Sardinian natural zeolites ${ }^{31}$.

\section{CONCLUSION}

The contribution of Cd (II) ion interactions in solutions with NIP and Cd (II)-IIP adsorbents determined by sequential desorption is dominated by the formation of hydrogen bonds. The interaction by forming hydrogen bonds between Cd (II) ions with Cd (II)-IIP adsorbents is not very strong, so the Cd (II) ion is easily removed and the adsorbent can be reused for several times of adsorption.

\section{ACKNOWLEDGMENT}

Thanks to Directorate General for Research and Development, Ministry of Research, Technology and Higher Education, Republic of Indonesia, especially the Directorate of Research and Community Service which has provided funds, opportunities, and confidence in conducting this research with Contract Number: 062/SP2H/LT/DPRM/2018. The authors also would like to thank Technical Service Unit of the Integrated Laboratory and the Technology Innovation Center-University of Lampung (UPT Laboratorium Terpadu dan Sentra Inovasi Teknologi-Universitas Lampung).

\section{REFERENCES}

1. Buhani, Rinawati, Suharso, D.P. Yuliasari and S.D. Yuwono, Desalin. Water Treat., 80, 203 (2017), DOI: 10.5004/dwt.2017.20932

2. Buhani, Narsito, Nuryono, E.S. Kunarti and Suharso, Desalin. Water Treat., 55(5), 1240 (2015), DOI: 10.1080/19443994.2014.924880

3. Buhani, Suharso and Z. Sembiring, Orient. J. Chem., 28(1), 271 (2012)

4. Buhani, Suharso and Sumadi, Asian J. Chem., 24(1), 133 (2012)

5. Suharso and Buhani, Asian J. Chem., 23(3), 1112 (2011)

6. Buhani and Suharso, Asian J. Chem., 21(5), 3799 (2009)

7. Rahmi and Lelifajri, Rasayan J. Chem., 10(2), 634 (2017), DOI: 10.7324/RJC.2017.1021736

8. Y.A.B. Neolaka, E.B.S. Kalla, G. Supriyanto, Suyanto and N.N.T. Puspaningsih, Rasayan J. Chem., 10(2), 606 (2017), DOI: 10.7324/RJC.2017.1021710

9. K. Anitha, S. Karthikeyan and P.S.S. Shabudeen, Rasayan J. Chem., 7(4), 308 (2014)

10. D.J. Shaw, Introduction to Colloid and Surface Chemistry, $3^{\text {th }}$ edition, Butterworth and Co. Ltd., New York (1983).

11. M.M. Montazer-Rahmati, P. Rabbani, A. Abdolali and A.R. Keshtkar, J. Hazard. Mater., 185, 401407 (2011), DOI: 10.1016/j.jhazmat.2010.09.047

12. Y.G. Bermüdez, I.L.R. Rico, O.G. Bermüdez and E. Guibal, Chem. Eng. J., 166, 122-131 (2011), DOI: 10.1016/j.cej.2010.10.038

13. Buhani, Suharso and L. Aprilia, Indo. J. Chem., 12(1), 94 (2012). 
14. Buhani, Suharso and H. Satria, Eur. J. Scientific Res., 51(4), 467-476 (2011).

15. X. Chang, N. Jiang, H. Zheng, Q. He, Z. Hu, Y. Zhai and Y. Cui, Talanta, 71, 38-43 (2007), DOI: 10.1016/j.talanta.2006.03.012

16. F. Li, H. Jiang and S. Zhang, Talanta, 71, 1487-1493 (2007), DOI: 10.1016/j.talanta.2006.07.023

17. J. Zhao, B. Han, Y. Zhang and D. Wang, Anal. Chim. Acta, 603, 87-92 (2007), DOI: 10.1016/j.aca.2007.09.024

18. Y. Zhai, Y. Liu, X. Chang, X. Ruan and J. Liu, React. \& Funct. Polymers, 68, 284-291 (2008), DOI: 10.1016/j.reactfunctpolym.2007.08.013

19. M.H. Arbab-Zavar, M. Chamsaz, G. Zohuri and A. Darroudi, J. Hazard. Mater., 185, 38-43 (2011), DOI: 10.1016/j.jhazmat.2010.08.093

20. Buhani, Narsito, Nuryono and E.S. Kunarti, Desalination, 251, 83-89 (2010), DOI: 10.1016/j.desal.2009.09.139

21. D. Pérez-Quintanilla, A. Sanchez, I. del Hierro, M. Fajardo and I. Sierra, J. Colloid Interface Sci., 313, 551-562 (2007), DOI: 10.1016/j.jcis.2007.04.063

22. E.F.C. Alcantara, E.A. Faria, D.V. Rodrigues, S.M. Evangelista, E. De Oliveira, L.F. Zara, D. Rabelo and A.G.S. Prado, J. Colloid Interface Sci., 311, 1-7 (2007), DOI: 10.1016/j.jcis.2007.02.075

23. P.K. Jal, S. Patel and B.K Mishra, Talanta, 62, 1005-1028 (2004), DOI: 10.1016/j.talanta.2003.10.028

24. D. Pérez-Quintanilla, I. del Hierro, M. Fajardo and I. Sierra, J. Hazard. Mater., 134(1-3), 245-256 (2006), DOI: 10.1016/j.jhazmat.2005.11.004

25. A.E. Martell and R.D. Hancock, Metal Complexes in Aqueous Solution, Plenum Press, New York (1996).

26. Buhani, Narsito, Nuryono and E.S. Kunarti, Indo. J. Chem., 9(2), 170-176 (2009)

27. J.E. Huheey, E.A. Keiter and R.L. Keitler, Inorganic Chemistry: Principles of Structure as and Reactivity, $4^{\text {th }}$ Edition, Harper, Collins Collage Publisher, New York, p: 345-347 (1993).

28. F.M.M. Morel and J.G. Hering, Principles and Application of Aquatic Chemistry, John Wiley \& Sons, Inc., New York, p: 332-342 (1993).

29. M. Alam, M. Aslam and S. Rais, Rasayan J. Chem., 2(4), 791 (2009)

30. I. Uzun and F. Güzel, Turk. J. Chem., 24, 291 (2000)

31. A. Cincotti, A. Mameli, A.M. Locci, R. Orru and G. Cao, Ind. Eng. Chem. Res., 45, 1074 (2006), DOI: $10.1021 / \mathrm{ie} 050375 \mathrm{z}$

[RJC-2084/2018] 